\title{
Existing data sources for clinical epidemiology: the Danish Patient Compensation Association database
}

This article was published in the following Dove Press journal:

Clinical Epidemiology

17 July 2015

Number of times this article has been viewed

\author{
Jens Tilma' \\ Mette Nørgaard' \\ Kim Lyngby Mikkelsen² \\ Søren Paaske Johnsen' \\ 'Department of Clinical Epidemiology, \\ Aarhus University Hospital, Aarhus, \\ ${ }^{2}$ Danish Patient Compensation \\ Association, Copenhagen, Denmark
}

\begin{abstract}
Any patient in the Danish health care system who experiences a treatment injury can make a compensation claim to the Danish Patient Compensation Association (DPCA) free of charge. The aim of this paper is to describe the DPCA database as a source of data for epidemiological research. Data to DPCA are collected prospectively on all claims and include information on patient factors and health records, system factors, and administrative data. Approval of claims is based on injury due to the principle of treatment below experienced specialist standard or intolerable, unexpected extensiveness of injury. Average processing time of a compensation claim is 6-8 months. Data collection is nationwide and started in 1992. The patient's central registration system number, a unique personal identifier, allows for data linkage to other registries such as the Danish National Patient Registry. The DPCA data are accessible for research following data usage permission and make it possible to analyze all claims or specific subgroups to identify predictors, outcomes, etc. DPCA data have until now been used only in few studies but could be a useful data source in future studies of health care-related injuries.
\end{abstract}

Keywords: public health care, treatment injuries, no-fault compensation, registries, research, Denmark

\section{Introduction}

The majority of the population in developed countries has at least one contact with the health care system each year. In the US, $82.1 \%$ of adults and $92.8 \%$ of children were in contact with the health care system in $2012 .{ }^{1}$ In Denmark, $95 \%$ of all residents are in contact with the health care system corresponding to 1.1 million admissions to hospitals, 11.5 million outpatient visits at hospitals, 11.5 million visits to privately practicing specialists, and 40.5 million general practitioner visits in $2012 .{ }^{2}$ The high activity will inevitably lead to health care-related patient injuries as a result of either adverse events (AEs) or errors. The reported incidence of AEs varies between countries and health care systems (ie, from $2.9 \%$ of all admissions in Utah and Colorado, US, to $16.6 \%$ in New South Wales and South Australia). ${ }^{3,4}$

Globally, the awareness and focus on patient safety have increased over the last decades. ${ }^{5}$ Several procedures and initiatives (eg, safety checklists before surgical procedures $^{6}$ and programs for prevention of central line-associated blood stream infections $)^{7}$ have been launched and implemented in order to improve patient safety and quality of care. Still, data on the effectiveness of interventions aimed at reducing the risk of AEs and errors remain sparse. Preferably, we would have data documenting the effects of interventions by showing the change of risk in the intervened areas of health care. If sufficiently detailed, these data might also reveal the characteristics
Department of Clinical Epidemiology, Aarhus University Hospital, Olof Palmes Allé 43-45, DK-8200, Aarhus N, Denmark. Email jent@clin.au.dk submit your manuscript | www.dovepress.com

Dovepress

http://dx.doi.org//0.2147/CLEP.S84162 
of injuries and the patients to whom they occur. A potential source of insights into patient safety is the growing amounts of data on health care-related injuries, which are collected as part of patient insurance and compensation administration. ${ }^{8}$ Herein often included are incidence, high-risk regions, and specialties, and differences among these categories may be observed - all valuable information when building a dataset to help understand the challenges in patient safety and decide where to focus preventive effort and thereby improve health care.

Data gathering is easier when high-completeness registries are present and ongoing updated. Denmark has a long tradition of collecting information on health care for the entire population in publicly governed registries. It is possible to link the registries at the individual level by the Civil Registration System (CRS)-number - a personal identifier given to every citizen at birth or immigration. ${ }^{9-12}$

With this paper, we aim to present the Danish Patient Compensation Association (DPCA) database and outline the research potential in the database. The DPCA is the organization responsible for managing the claims and compensation of injured patients in Denmark.

\section{Danish health care system}

The health care system in Denmark guarantees free access to hospital admissions, outpatient treatment, and visits to general practitioners. It is publicly funded in the vast majority of its function as only approximately $15 \%$ of the costs are paid by own expense, mainly out-of-pocket expenditure on pharmaceuticals and dentistry. If a citizen contracts an illness, he/she will usually be seen by a general practitioner who is a part of the primary health care. From there, it is possible to be referred to a specialist or a hospital. A patient is intended to be treated on the least specialized level to maintain an effective and relevant treatment without too much or too expensive actions, in order to give all patients the best treatment. ${ }^{13}$

\section{DPCA}

The DPCA was founded in 1992 in order to improve the patients' access to compensation following the passing of the Patient Insurance Act. According to the act, patients are to be compensated if they unexpectedly suffer injury while being treated anywhere in the entire Danish health care system. The DPCA functions as a no-fault system of claims, and the claimants are not charged any expenses for the casework.

Before 1992, compensation for an injury could only be obtained through the courts based on legal proof of an error by a health care professional. In practice, this meant that only a minority of patients with injuries received compensation. Following the passing of the Patient Insurance Act, legal proofs of errors are no longer required, but it is highly likely that the injury is related to the patient's treatment or examination. The DPCA as an institution gathers information on the case and decides the outcome, thereby assuring legal compensation in accordance with the Patient Insurance Act. In 1996, it was accompanied by the Act on Compensation for Medicine-Related Injuries. Since then, the area covered by the law has been expanded to include almost all areas and functions of the public and private health service. Both laws are now collected in the Danish Act on the Right to Complain and Receive Compensation within the Health Service, and claims are ruled according to this. The covered health care areas are listed in Table 1.

All patients who suffer injury in the public and private health care system can file a claim as long as the health care person is authorized by the National Board of Health. The DPCA is predominately tax funded through two sources: the Danish Regions, who finance the compensation for the public treatment injuries, and the Ministry of Health and Prevention, who finance the compensation for the medicine-related injuries. Private health care providers besides funded from public health care must take out a health care provider insurance on their own; however, this

Table I The health care areas covered by the Danish Patient Compensation Association

\section{Public and private hospitals}

Treatment in the ambulance or at the location of the injury Injuries on donors or test subjects/patients (if they are part of a medical test where a hospital, a governmentally funded educational unit, or a general practitioner is in direct charge)

General practitioners and doctors from the emergency service

Private practicing specialists

General practicing dentists (claims should be directed to the collective insurance under the Dental Association in Denmark), dental therapists, and clinical dental therapists

General practicing chiropractors, occupational therapists,

physiotherapists, and podiatrists

General practicing psychologists

General practicing nurses, midwives, clinical dietitians, medical laboratory technicians, surgical appliance makers, radiographers, opticians/contact lens opticians, and social and health care workers Authorized health care workers within the public health care services and the regional dental care and so on

The National Board of Health in the event that patients who are being treated for life-threatening cancer and heart diseases are exposed to mistakes in connection to the National Board of Health's case handling Preventative health care systems for children and teenagers, the home nursing care system, dental care for children and teenagers, rehabilitation offers, and treatment for alcohol and drug abuse 
does not affect the process of filing a claim from a patient's perspective. The tortfeasors (committer of the tort; commonly the hospital, administratively governed and financed by the region) account for the administration fee.

In 2012, a total of 9,628 claims were made to the DPCA. Of these, $33.1 \%$ were accepted and granted a total of $143,949,117$ USD. ${ }^{14}$ Figure 1 shows the annual number of approved and dismissed claims from 1996 to 2013.

\section{DPCA database}

The DPCA database consists of claims from all of Denmark. Digital data collection has been made since the start of DPCA in 1992. Until 2006, there were no systematic digital data on medical records, diagnostic imaging, specialist doctor's assessment, legal justification for decision, and additional material for case disclosure; however, data were stored in an analog form and are accessible upon payment of transport expenses. Table 2 shows the data recorded in the DPCA database, which includes information on the patient, the alleged injury, and information used to resolve the ruling.

When a claim is filed, a new folder is made for each case coded with a unique case number in addition to the CRS-number. Information is obtained from the patient's claim, medical records, a report from the place of treatment, remarks from the patient about the report, and possibly additional information from other places of treatment and specialist assessments. An overview of the distribution of reasons for approving claims among the approved treatment injury claims in 2012 is presented in Figure 2A. The development of this distribution was somewhat constant in the years 2007-2012, which is shown in Figure 2B. The most common cause was suboptimal diagnosis and/or treatment, below experienced specialist standard. For example:

1. A 53-year-old man was treated with corticosteroids for COPD. Six years later, he needed surgery because of vertebral compression fractures. It was considered below specialist standard that he was not followed up by a bone density scan and treated with vitamin-D, calcium, and possibly bisphosphonates.

2. A 35-year-old woman received smoking cessation treatment. First time, she started smoking again. Second time, she experienced adverse effect in the form of shortlasting faints and stopped treatment. She was started up a third time on the same drug because of a persistent wish for smoking cessation, but experienced breast pain and died from a coronary artery blood clot. The DPCA considered the incident most likely to stem from the treatment. Giving the same treatment the third time was considered below specialist standard.

The approved treatment injury claims constituted 33.1\% of all closed claims in 2012 (2,783 out of 8,408). We only included data until the year 2012, because it is the most recent year with sufficient data due to the data lag arising from the often long time period from the time of the injury to the final decision of making the claim. The lag time may be up to a few years.

A caseworker and usually an in-house specialist doctor will decide whether an injury has occurred, and if so, whether

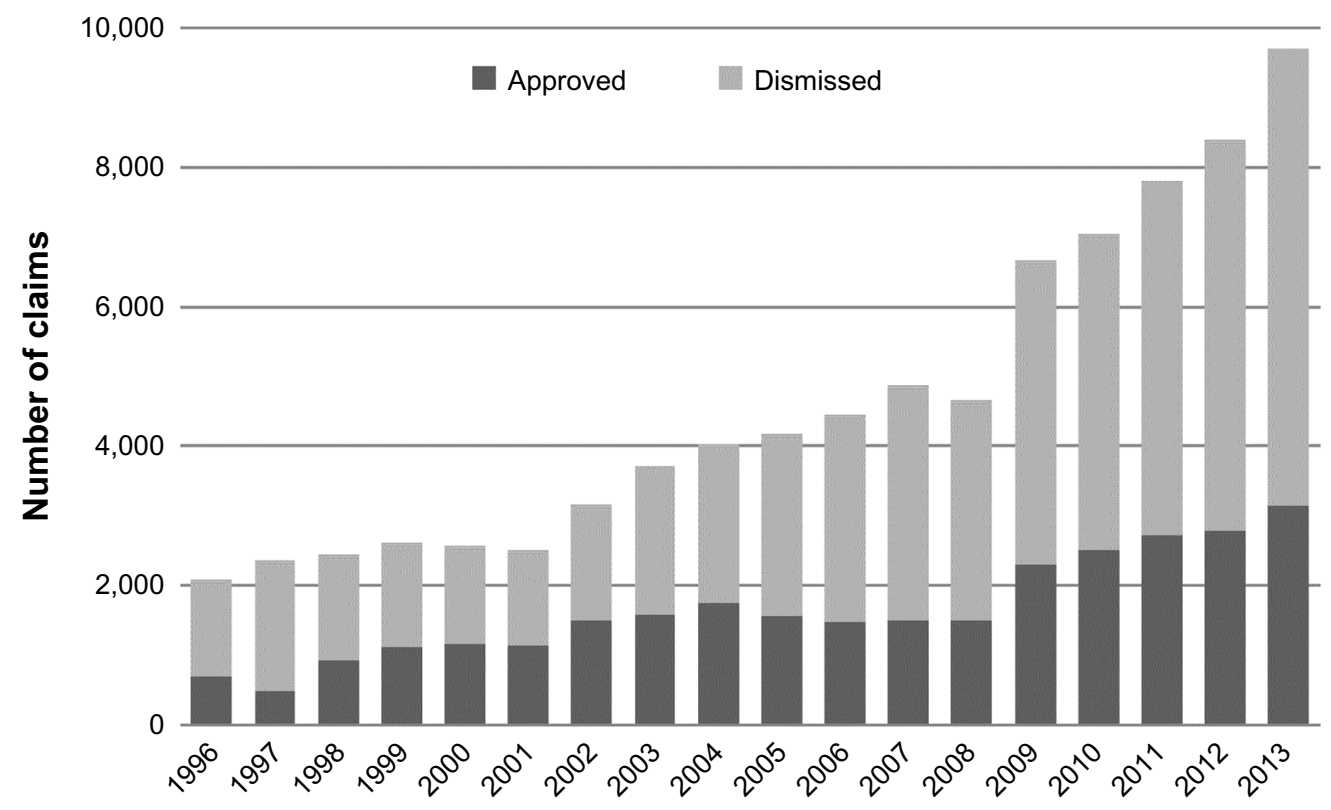

Figure I The number of claims closed by the Danish Patient Compensation Association per year from I996 to 2013, shown as approved and dismissed. 
Table 2 The collected data available in the Danish Patient Compensation Association database

\begin{tabular}{|c|c|c|}
\hline Patient & Setting & Administration \\
\hline CRS-number & $\begin{array}{l}\text { Institution } \\
\text { causing the } \\
\text { injury }\end{array}$ & Archive $\mathrm{nr}$ \\
\hline Age & Region code & Case $\mathrm{nr}$ \\
\hline Sex & Hospital code & $\begin{array}{l}\text { Decision of the claim by } \\
\text { the DPCA }\end{array}$ \\
\hline Basic diagnoses & $\begin{array}{l}\text { Setting } \\
\text { (admission, } \\
\text { outpatient, } \\
\text { acute, etc) }\end{array}$ & $\begin{array}{l}\text { Decision of first appeal } \\
\text { (to the National Agency } \\
\text { for Patients' Rights and } \\
\text { Complaints) }\end{array}$ \\
\hline Basic treatments & $\begin{array}{l}\text { Category of } \\
\text { personnel } \\
\text { (consultant, } \\
\text { other) }\end{array}$ & $\begin{array}{l}\text { Decision of second appea } \\
\text { (to the Court of Law) }\end{array}$ \\
\hline $\begin{array}{l}\text { Complications due to } \\
\text { treatment }\end{array}$ & Specialty & $\begin{array}{l}\text { Lex Maria (typical degree } \\
\text { of injury in case of } \\
\text { current complication) }\end{array}$ \\
\hline $\begin{array}{l}\text { Treatment of } \\
\text { complication }\end{array}$ & & $\begin{array}{l}\text { Status of claim (closed, } \\
\text { pending, other) }\end{array}$ \\
\hline Date of complication & & Date of registry \\
\hline Death & & Date of decision \\
\hline $\begin{array}{l}\text { Death caused by } \\
\text { treatment }\end{array}$ & & $\begin{array}{l}\text { Judgment in court } \\
\text { (if appealed) }\end{array}$ \\
\hline Date of injury & & $\begin{array}{l}\text { Compensation in total } \\
\text { DKR }\end{array}$ \\
\hline \multicolumn{3}{|l|}{ Degree of injury } \\
\hline \multicolumn{3}{|l|}{ Loss of earning capacity } \\
\hline $\begin{array}{l}\text { Additional days of pain } \\
\text { and suffering }\end{array}$ & & \\
\hline
\end{tabular}

Abbreviations: CRS, Civil Registration System; nr, number; DPCA, Danish Patient Compensation Association; DKR, Danish Krone.

it is entitled to compensation. The average processing time of a claim is $6-8$ months regarding compensability. To determine the size of compensation, additional information is often requested, eg, receipts of drugs, transportation expenses, a doctor statement(s) regarding the degree of injury, and loss of earning capacity. This process might take up to 1 year, though most of the compensation is paid immediately after compensability decision. Figure 3 describes the casework of a claim.

\section{Data linkage possibilities}

Linking data from the DPCA database with other populationbased health care registers is a relatively simple yet powerful way of increasing the depths of the claims data. Data in the DPCA database always include a patient's CRS-number. Since this number is included in all public registries and databases in Denmark, it is feasible to link the data from the DPCA database to a wide range of other data sources.
Numerous registries are kept in Denmark spanning from birth to death of every Danish citizen, and therefore, through record linkage, it is possible to obtain more detailed data on patients characteristics (including data on clinical, demographic, geographic, and socioeconomic variables) and to perform long-term follow-up (eg, on mortality, readmissions, or return to work) on the patients registered in the DPCA database. ${ }^{9}$ The Danish National Registry of Patients is an example of a registry that will often be relevant to consider in relation to record linkage with the DPCA database as it holds detailed data on all admissions to Danish hospitals since 1977 and also on visits to outpatient clinics and emergency room visits since $1995 .^{15}$

The DPCA database covers treatment injuries reflected by compensation claims. Another separate agency, the National Agency for Patients' Rights and Complaints (NAPRC), receives all complaints regarding the health care system, the appeals from the DPCA rulings, and the reports of AEs for registration and learning. Reported AEs go into the Danish Patient Safety Database (DPSD) under the NAPRC; however, the DPSD does not contain CRS-numbers and record linkage with other data sources; individual identification is therefore not possible. The AE data comprise major, minor, or even trivial (potential and actually occurred) injuries; hence, the number of AE reports is substantially higher than the number of compensation claims. Data linkage to other registries from the DPSD would potentially give insight into causes of AEs in general and highlight high-risk patient groups on a broader scale than treatment injuries eligible for compensation. The DPCA data relate to NAPRC data in the way that approved compensation claims in the DPCA ought to be a subset of AEs in the DPSD, if the registration of both compensation claims and reporting AEs was complete. Complaints to the NAPRC do not necessarily reflect treatment injuries, but is often caused by dissatisfaction (eg, due to poor communication); however, an overlap is possible, since the systems for complaints and claims are separate.

\section{Strengths and limitations}

The DPCA database holds detailed data, which, except for trivial cases, are evaluated by specialist doctors on the different medical areas. However, only patients who actually file a claim are registered in the DPCA database, and therefore, estimates based on DPCA data will underestimate the true incidence of injuries occurring in the Danish health care system. Unfortunately, the potential underreporting of eligible compensation claims to the DPCA and the influencing factors has not yet been evaluated. Underreporting is 


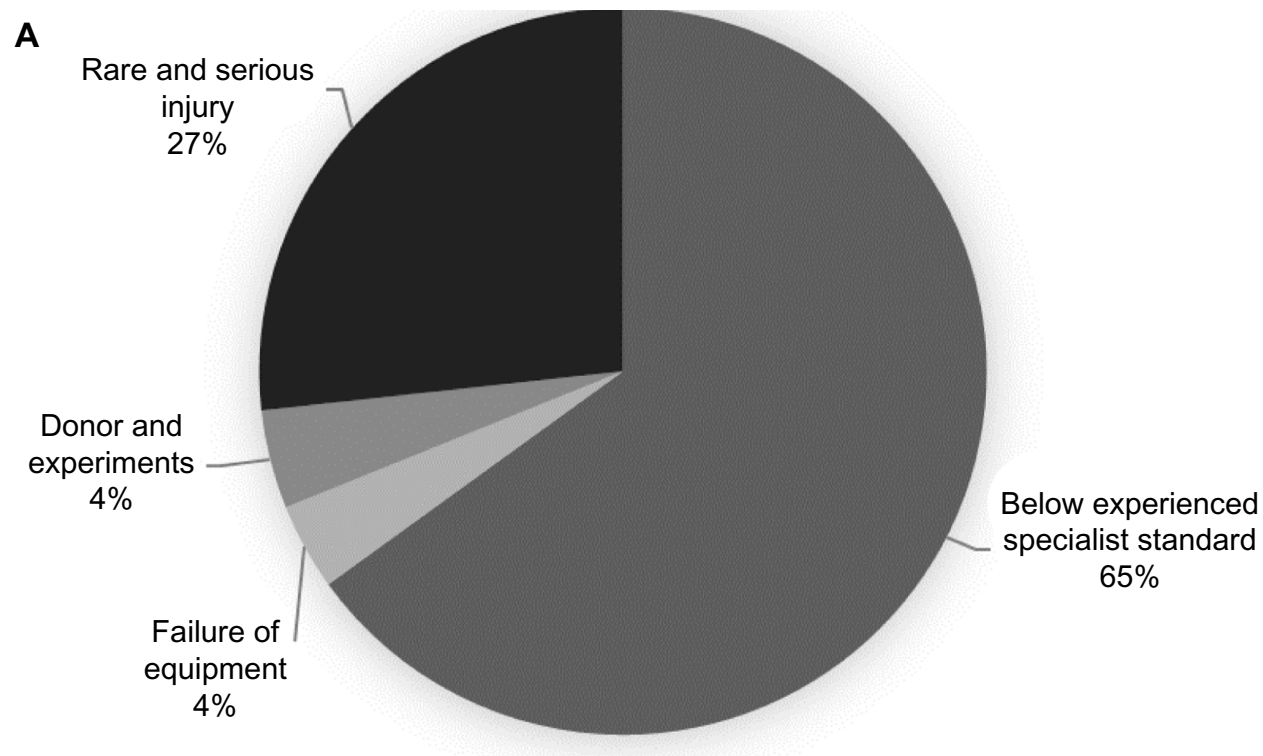

B

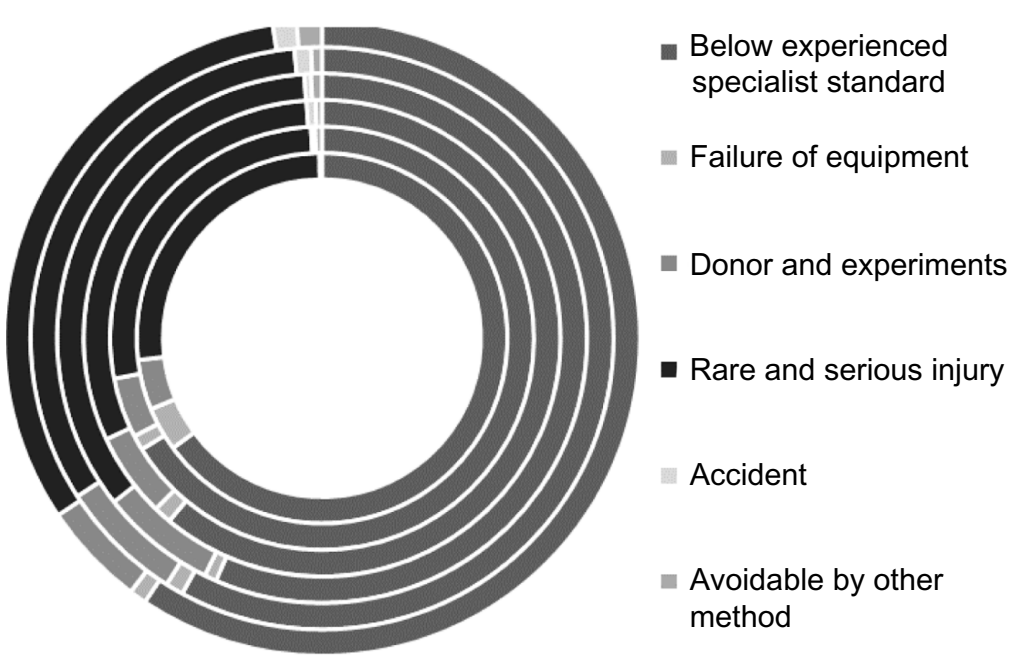

Figure 2 The distribution of the reasons for approving claims filed to the Danish Patient Compensation Association in (A) 2012 and (B) $2007-2012$ with 2012 in the innermost circle and 2007 in the outer circle, respectively.

Note: The categories accident and avoidable by other method are not shown, because they comprise $\approx 0 \%$ of the approval reasons $(0.07 \%$ and $0.14 \%$, respectively).

known from other health care systems, eg, in New York State, only $1.53 \%$ (95\% CI $0.00 ; 3.24)$ of AEs caused by medical negligence resulted in a claim. ${ }^{16}$ Likewise, a study from New Zealand found that only $0.4 \%$ of AEs and $4 \%$ of the preventable AEs resulted in a complaint. ${ }^{17}$ Patients with permanent and fatal injuries were more likely to file a complaint than patients with temporary injuries (odds ratio 11.4, 95\% CI 5.9;22.1 and odds ratio 17.9, 95\% CI 9.3;34.2, respectively). ${ }^{17}$ Another study from New Zealand reported that only $2.9 \%$ of patients eligible for compensation actually filed a claim to their no-fault system of treatment injury compensation. ${ }^{18}$

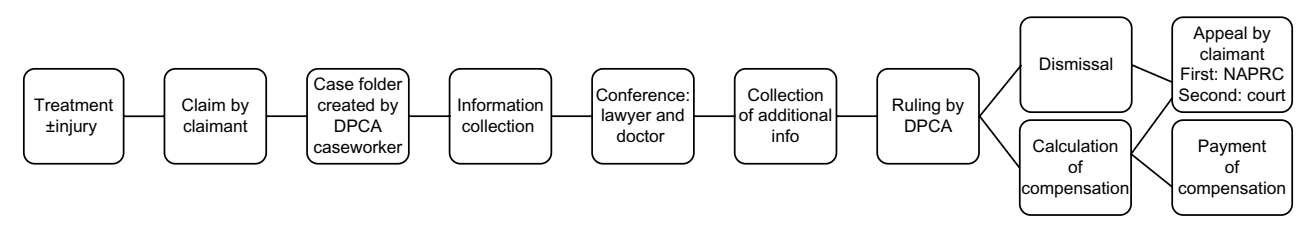

Figure 3 Flowchart of casework.

Abbreviations: DPCA, Danish Patient Compensation Association; NAPRC, National Agency for Patients' Rights and Complaints. 
Although AEs in the Danish health system are to be reported to the DPSD, this is not always fulfilled. A survey of the DPSD reporting system in 2006 suggested a maximum reporting of $85 \%$ of the AEs. In 2010, the proportion of reported AEs was estimated to be as low as $15 \%{ }^{14,19}$ despite increasing report counts of 12,370 in 2006 to 155,791 in $2012 . .^{20}$ The real number of AEs and treatment injuries in the Danish health care system therefore remains unknown. A contributing factor to the rise of $\mathrm{AE}$ reports and compensation claims is an increasing public knowledge of the existence of the compensation system and increased willingness to report injuries and seek compensation. The true incidence of AEs and injuries may therefore not be increasing or at least not as much as the increasing number of reports suggests. ${ }^{21}$ Still, the fact that a substantial proportion of the complaints that are being filed concerns severe and potentially preventable injuries, ${ }^{17}$ and the minor effort needed to file a claim together with no financial demands to do so, indicates that the DPAC database gives a potentially valuable insight on serious threats to patient safety. Furthermore, the de minimis threshold for compensation is $10,000 \mathrm{DKR}(\approx 1,500 \mathrm{USD})$, filtering off minor and potential (AEs includes potentially harmful events) injuries from the approved claims and selecting more serious cases in the database. Therefore, DPCA data may potentially guide injury preventive efforts to improve health care quality.

\section{Examples of studies using DPCA data}

Data from the DPCA database have been used in a number of studies within recent years. In a study based on all closed claims concerning medical-related deaths in the Danish primary health care and hospital setting from 1996 to 2008, Hove et al identified 836 deaths caused by treatment or lack of treatment in the period of 1996-2008 with a total cost of compensation at 55 million USD. According to the DPCA, 435 (52\%) deaths were preventable. ${ }^{22}$

Another study examined patient safety at labor wards according to ward size (number of deliveries per year). The study was based on DPCA data on approved claims of obstetric injuries linked with data from the National Birth Registry. The approval rate of claims was lowest in large labor units (34.2\%), higher in very large (38.6\%) and intermediate labor units (41.7\%), and highest in small labor units $(50.0 \%)$. The study concluded that the results might reflect that large labor units are living up to the principle of best practice to a greater degree. ${ }^{23}$
An updated list of scientific publications based on DPCA data is available at the website http://patienterstatningen. dk/da/Udgivelser-og-tal/Faglige-artikler.aspx.

Compensation claims contribute to the organization of the health care system on different levels. On a single case level, a compensation claim can function as a feedback system, eg, a general practitioner and practicing specialist missed a breast cancer diagnosis due to an inappropriate procedure of pathology responses. Because of the awareness from the compensation claim, they changed the information flow channels in both clinics. Studies based on multiple claims offer the foundation of knowledge to better organize health care, eg, the question of consolidating specific departments, especially labor wards, in central units with a higher volume of contacts has been influenced by these patients' safety evaluations.

A further research potential of the DPCA database is large, because individual level identification, medical records, and data linkage are available. The DPCA data might be used to validate approved compensation claims as a measure of the treatment injuries, to investigate predictors of treatment injuries in general, to identify high-risk areas and quality of health care, and to compare information value from these data compared to AEs, complaints, and others.

Other databases arising from compensation claims are present internationally, eg, those in the People's Republic of China described by Li et al, ${ }^{24}$ in New Zealand used by Davis et $\mathrm{al},{ }^{25}$ and in the US used by Brown et al. ${ }^{26}$

\section{Accessing DPCA data}

Data files are stored by the DPCA (http://www.patienterstatningen.dk). From the database, the data are accessed by the lawyers and doctors of the DPCA to rule in the claims, and the data are coded and published in annual reports by the DPCA and in medical journals by researchers. Authorized health care researchers can be granted access to the database by contacting the medical coordinator at DPCA, Kim Lyngby Mikkelsen (kim.lyngby.mikkelsen@patienterstatningen.dk).

The use of any personal data, including health data, is protected by the Danish Act on Processing of Personal Data, and a specific permission from the Data Protection Agency is required (http:// www.datatilsynet.dk). This permission is a formality if the project satisfies the following: follows the data protection legislation, the objectives are relevant from a clinical and societal perspective, and the project is affiliated to a Danish research institution.

\section{Conclusion}

The DPCA database holds valuable information on treatment injuries in the Danish health care system. The approved 
closed claims are indicative of partly or totally preventable injuries and are therefore of great interest in designing efficient preventive initiatives and a health care system with better patient safety.

\section{Acknowledgment}

This work was supported by a grant from the Tryg Foundation.

\section{Disclosure}

The authors report no conflict of interests.

\section{References}

1. FASTSTATS - doctor visits. Available from: http://www.cdc.gov/nchs/ fastats/physician_visits.htm. Accessed June 4, 2014.

2. Regioner - fakta om sundhedsvæsenet - sundhedsvæsenet i tal. [Regions - facts in the health care system - health care in numbers]. Available from: http://www.regioner.dk/aktuelt/temaer/fakta+om+reg ionernes + effektivitet + og $+\varnothing$ konomi/kopi + af + fakta + om + sundhedsvæs enet. Accessed March 27, 2014. Danish.

3. Thomas EJ, Studdert DM, Burstin HR, et al. Incidence and types of adverse events and negligent care in Utah and Colorado. Med Care. 2000;38(3):261-271.

4. Wilson RM, Runciman WB, Gibberd RW, Harrison BT, Newby L, Hamilton JD. The quality in Australian health care study. Med J Aust. 1995;163(9):458-471.

5. Stelfox HT, Palmisani S, Scurlock C, Orav EJ, Bates DW. The "to err is human" report and the patient safety literature. Qual Saf Health Care. 2006;15(3):174-178.

6. Bergs J, Hellings J, Cleemput I, et al. Systematic review and metaanalysis of the effect of the World Health Organization surgical safety checklist on postoperative complications. Br J Surg. 2014;101(3): $150-158$.

7. Berenholtz SM, Lubomski LH, Weeks K, et al; On the CUSP: Stop BSI Program. Eliminating central line-associated bloodstream infections: a national patient safety imperative. Infect Control Hosp Epidemiol. 2014;35(1):56-62.

8. Pegalis SE, Bal BS. Closed medical negligence claims can drive patient safety and reduce litigation. Clin Orthop Relat Res. 2012;470(5):1398-1404.

9. Frank L. When an entire country is a cohort. Science. 2000; 287(5462): 2398-2399.

10. Storm HH, Michelsen EV, Clemmensen IH, Pihl J. The Danish cancer registry - history, content, quality and use. Dan Med Bull. 1997;44(5):535-539.

11. Thygesen LC, Daasnes C, Thaulow I, Bronnum-Hansen H. Introduction to Danish (nationwide) registers on health and social issues: structure, access, legislation, and archiving. Scand J Public Health. 2011; 39(7 Suppl): $12-16$.

12. Pedersen CB. The Danish civil registration system. Scand J Public Health. 2011;39(7 Suppl):22-25.

Clinical Epidemiology

\section{Publish your work in this journal}

Clinical Epidemiology is an international, peer-reviewed, open access, online journal focusing on disease and drug epidemiology, identification of risk factors and screening procedures to develop optimal preventative initiatives and programs. Specific topics include: diagnosis, prognosis, treatment, screening, prevention, risk factor modification,

Submit your manuscript here: http://www.dovepress.com/clinical-epidemiology-journal
13. Ministry of Health and Prevention. Health care in Denmark. [Danish Health Care]; 2008. Available from: http://www.sum.dk/Aktuelt/ Publikationer/ /media/Filer\%20-\%20Publikationer_i_pdf/2008/ UK_Healthcare_in_dk/pdf.ashx. Accessed March 18, 2014.

14. Danish Patient Insurance Association. DPIA annual report of 2010-2012 in numbers regarding claims and compensations; 2013. Available from: http://patienterstatningen.dk/da/Udgivelser-og-tal/Statistik/\%/media/Files/ Statistik/Statistik\%202012/hel\%C3\%A5rstal_2010_2012_12.ashx.

15. Andersen TF, Madsen M, Jorgensen J, Mellemkjoer L, Olsen JH. The Danish national hospital register. A valuable source of data for modern health sciences. Dan Med Bull. 1999;46(3):263-268.

16. Localio AR, Lawthers AG, Brennan TA, et al. Relation between malpractice claims and adverse events due to negligence. Results of the Harvard medical practice study III. N Engl J Med. 1991;325(4):245-251.

17. Bismark MM, Brennan TA, Paterson RJ, Davis PB, Studdert DM. Relationship between complaints and quality of care in New Zealand: a descriptive analysis of complainants and non-complainants following adverse events. Qual Saf Health Care. 2006;15(1):17-22.

18. Bismark MM, Brennan TA, Davis PB, Studdert DM. Claiming behavior in a no-fault system of medical injury: a descriptive analysis of claimants and non-claimants. Med J Aust. 2006;185(4):203-207.

19. Rambøll Management. Evaluation on act on patient safety [Evaluering af lov om patientsikkerhed]. Danish Domestic and Health Ministry; 2006. Available from: http://dpsd.demo.privatsite.dk/ /media/Foundry/Sites/ DPSD/Files/Informationsmateriale/rapportevaluering.ashx. Accessed June 17, 2015. Danish.

20. Patientombuddet. Årsberetning 2012, dansk patientsikkerheds database del 1; 2013. [The National Agency for Patients' Rights and Complaints. Annual Report 2012, the Danish Patient Compensation Association Database, part 1]. Available from: http://dpsd.demo.privatsite.dk/ / media/Foundry/Sites/DPSD/Files/Aarsrapporter/2012_\%C3\%A5rsbe retning_dpsd_del_1_001.aspx. Accessed March 27, 2014. Danish.

21. Bast K, Graugaard O, Rasmussen C, Mortensen L. Stigningen i anmeldelser til og erstatningstilkendelser fra Patientforsikringen 2006-2011 - analyse af baggrunden og prognose for 2012-2015. [The increase in claims to and compensations from the Danish Patient Compensation Association 2006-2011 - analysis of the background and prediction for 2012-2015]. The Danish Patient Compensation Association; 2011. Available from: http://patienterstatningen.dk/da/Udgivelser-og-tal/ /media/Files/Artikler/ Rapport\%2009032012.ashx. Accessed June 17, 2015. Danish.

22. Hove L, Bock J, Christoffersen J, Dam H. An analysis of closed claims related to death in the Danish health care system. Int J Med Med Sci. 2012;2(10):197-203.

23. Milland M, Christoffersen JK, Hedegaard M. The size of the labor wards: is bigger better when it comes to patient safety? Acta Obstet Gynecol Scand. 2013;92(11):1271-1276.

24. Li H, Wu X, Sun T, et al. Claims, liabilities, injures and compensation payments of medical malpractice litigation cases in China from 1998 to 2011. BMC Health Serv Res. 2014;14:390.

25. Davis P, Lay-Yee R, Fitzjohn J, Hider P, Briant R, Schug S. Compensation for medical injury in New Zealand: does "no-fault" increase the level of claims making and reduce social and clinical selectivity? $J$ Health Polit Policy Law. 2002;27(5):833-854.

26. Brown TW, McCarthy ML, Kelen GD, Levy F. An epidemiologic study of closed emergency department malpractice claims in a national database of physician malpractice insurers. Acad Emerg Med. 2010; 17(5):553-560.

\section{Dovepress}

systematic reviews, risk \& safety of medical interventions, epidemiology \& biostatistical methods, and evaluation of guidelines, translational medicine, health policies \& economic evaluations. The manuscript management system is completely online and includes a very quick and fair peer-review system, which is all easy to use. 